\title{
Mechanism and causes of failed transradial approach - our experience
}

\author{
Jogen Patrk*, Dražen Zekanović, Ante Anić, Zorislav Šušak, Zoran Bakotić, Davor Nekić, \\ Albino Jović \\ Zadar General Hospital, Zadar, Croatia
}

Background: The transradial approach (TRA) for percutaneous coronary diagnostic and interventional procedures has been shown to decrease vascular complications and improve clinical outcomes compared with transfemoral approach (TFA). Despite its obvious advantages, TRA is still infrequently used in routine practice. Main disadvantages of TRA compared with TFA, beside the necessary learning curve is a variable rate of transradial failure due to specific problems related to this arterial access.

Objective: To evaluate the incidence and causes of TRA failure in coronary angiographies and interventional procedures performed in a large cohort of unselected patients in single center observational study.

Methods: All consecutive right TRA procedures performed at our institution between January 2011 and December 2012, by low-to-intermediate volume operators, were analyzed retrospectively.

Results: In the observed period we performed 1341 coronary diagnostic and interventional procedures, 1243 (92,7\%) were performed using right TRA as primary access. Mean age was 64.1 years, and $35 \%$ were female. TRA failure occurred in 75 procedures $(6.0 \%)$. In that subgroup, mean age was 68.3 and $61 \%$ were female. Two main causes of failed TRA were puncture failure in $32(42.6 \%)$ and unsuitable anatomy (i.e. tortuous subclavian and brachiocephalic arteries, radial loop, radial hypoplasia or abberant arteries) in 31 $(41.3 \%)$ patients. The remaining causes occurred at a much lower frequency: impassable radial spasm in 7 (9.3\%), technical difficulty in $3(4.0 \%)$ and vascular complications in 2 $(2.6 \%)$ cases. The procedure was successfully completed in all $75(100 \%)$ patients with TRA failure by switching to TFA.

Conclusions: TRA coronary procedures, even in acute coronary syndrome settings, can be performed in the intermediate volume center by low-to-intermediate volume operators, using standard and dedicated equipment with a low failure rate. Older age and female sex are predictors of TRA failure.

KEYWORDS: coronary artery disease, transradial approach, procedural failure.

Received: $27^{\text {th }}$ Feb 2013
*Address for correspondence: Opća bolnica Zadar, B. Peričića 5, HR-23000 Zadar,
Croatia.
Phone: +385-23-505-505
E-mail: jogen.patrk@ zd.t-com.hr

\section{Literature}

1. Rao SV, Cohen MG, Kandzari DE, et al. The transradial approach to percutaneous coronary intervention: historical perspective, current concepts, and future directions. J Am Coll Cardiol. 2010;55:2187-95.

2. Lukenda J. [Transradial approach in interventional cardiology: "quod licet femoralisti, non licet radialisti"]. Lijec Vjesn 2012;134:178-85.

3. Carrillo X, Mauri J, Fernandez-Nofrerias E, et al. Safety and efficacy of transradial access in coronary angiography: 8-year experience. J Invasive Cardiol. 2012;24(7):346-51.

4. Dehghani P, Mohammad A, Bajaj R, et al. Mechanism and predictors of failed transradial approach for percutaneous coronary interventions. JACC Cardiovasc Intervent. 2009;2(11):1057-64 